\title{
Pembuatan Biogas Dari Berbagai Limbah Cair Pabrik Kelapa Sawit
}

\author{
Irvan $^{1}$, Irma Suraya ${ }^{1}$, Hari Tiarasti ${ }^{1}$, Bambang Trisakti $^{1}$, Rosdanelli Hasibuan ${ }^{1}$, Yoshimasa Tomiuchi ${ }^{2}$ \\ ${ }^{1}$ Departemen Teknik Kimia, Fakultas Teknik, Universitas Sumatera Utara, \\ Jl. Almamater Kampus USU Medan 20115, Indonesia \\ irvan@usu.ac.id \\ ${ }^{2}$ R\&D Centre, METAWATER Co.,Ltd., \\ 7, Yawata-kaigandori, Ichihara-city, Chiba 290-8511, Japan \\ tomiuchi-yoshimasa@metawater.co.jp
}

\begin{abstract}
Abstrak
Penelitian ini bertujuan untuk memproduksi biogas dari limbah cair yang diperoleh dari berbagai pabrik kelapa sawit (PKS), sehingga diperoleh informasi limbah cair dari PKS mana yang memiliki potensi paling besar untuk digunakan sebagai bahan baku. Penelitian ini dilakukan pada skala laboratorium menggunakan tangki fermentor tipe continuous stirred tank reactor (CSTR) dengan volume 2 liter. Fermentor dilengkapi dengan pemanas untuk menjaganya bekerja pada kondisi termofilik yaitu temperatur $55^{\circ} \mathrm{C}$, mixer dan 2 unit pompa yang bekerja secara intermitten. Bahan kimia utama yang digunakan adalah natrium bikarbonat ( $\left.\mathrm{NaHCO}_{3}\right)$, amonium bikarbonat $\left(\mathrm{NH}_{4} \mathrm{HCO}_{3}\right)$ dan trace metals. Variabel-variabel yang diamati antara lain total solid (TS), volatile solid (VS), M-alkalinitas dan produksi biogas pada laju pengisian substrat atau hydraulic retention time (HRT) yang sama yaitu 6 hari. Dari hasil penelitian ini diperoleh bahwa pada HRT 6 hari, PKS PT. Sisirau memiliki produksi biogas tertinggi yaitu 12,7 liter/hari dan produksi biogas terendah berasal dari PKS Pagar Merbau sebesar 2,36 liter/hari. Kandungan TS dan VS yang tertinggi berasal dari PKS Sisirau sebesar $58.610 \mathrm{mg} / \mathrm{l}$ dan $45.400 \mathrm{mg} / \mathrm{l}$ sedangkan yang terendah berasal dari PKS Rambutan sebesar $42.000 \mathrm{mg} / \mathrm{l}$ dan $37.100 \mathrm{mg} / \mathrm{l}$.
\end{abstract}

Kata kunci : biogas, limbah cair pabrik kelapa sawit, termofilik, anaerobik

\begin{abstract}
The purpose of this research is to generate biogas from palm oil mill effluent (POME) taken from various palm oil mills, in order to obtain information which mill has the biggest potential to be used as raw material. Experiments were conducted at laboratory scale using a continuous stirred tank reactor (CSTR) with a volume of two liters. Reactor was equipped with heater to maintain its temperature at $55^{\circ} \mathrm{C}$ mixer and two pumps which work in intermittent mode. Main chemicals used in this research were sodium bicarbonate (NaHCO$)_{3}$, ammonium bikarbonat $\left(\mathrm{NH}_{4} \mathrm{HCO}_{3}\right)$, and trace metals. Observed variables were volume of biogas, total solid (TS) and volatile solid (VS), at hydraulic retention time (HRT) 6 days. The results of this study showed that at the same HRT, POME of PT. Sisirau has the highest biogas production, 12.7 liter/day, while Pagar Merbau's POME has the lowest biogas production, 2.36 liter/day. The highest content of TS and VS were from Sisirau's POME, 58,610 and 45,400 mg/l, respectively, while the lowest content were from Rambutan's POME, 42,000 mg/l for TS and $37,100 \mathrm{mg} / \mathrm{l}$ for VS.
\end{abstract}

Keywords : biogas, palm oil mill effluent (POME), thermophilic, anaerobic

\section{Pendahuluan}

Indonesia menjadi salah satu negara yang paling besar dalam produksi CPO (Crude Palm Oil). Namun timbul permasalahan baru yaitu makin banyaknya limbah yang dihasilkan [4]. Satu ton tandan buah segar (TBS) dapat dikonversi menjadi 0,2 ton CPO (Crude Palm Oil), sementara 0,66 ton akan dikonversi menjadi limbah cair pabrik kelapa sawit (LCPKS) [2]. Limbah tersebut dapat dimanfaatkan menjadi biogas. Kandungan utama dari biogas adalah metana. Pemanfaatan gas metana sebagai bahan bakar memiliki nilai ekonomis yang tinggi dan sesuai dengan skenario penurunan gas rumah kaca yang dituangkan dalam Clean Development Mechanism (CDM). Gas metana sebanyak $1 \mathrm{~m}^{3}$ setara dengan $0,65 \mathrm{~kg}$ gas elpiji (LPG). Maka, dengan penggunaan metana dapat menghemat penggunaan bahan bakar dari sumber unrenewable [6].

Beberapa hal yang menarik pada teknologi biogas adalah kemampuannya untuk membentuk biogas dari limbah organik yang jumlahnya berlimpah dan tersedia secara bebas. Variasi dari sifat-sifat biokimia menyebabkan produksi biogas juga bervariasi. Sejumlah bahan organik dapat digunakan bersama-sama dengan beberapa persyaratan produksi gas atau pertumbuhan normal bakteri metan yang sesuai. Beberapa sifat bahan organik tersebut mempunyai dampak yang nyata pada tingkat produksi gas [5].

Di dalam perencanaan pembuatan pabrik biogas, bahan baku limbah cair kelapa sawit sangat perlu diperhatikan. Oleh sebab itu, diperlukan penelitian untuk memperoleh informasi mengenai bahan baku limbah cair kelapa sawit dari pabrik kelapa sawit yang mana paling bagus untuk memproduksi biogas.

Teori

Biogas merupakan produk akhir dari degradasi anaerobik bahan organik oleh bakteri-bakteri anaerobik dalam lingkungan dengan sedikit oksigen. Komponen terbesar yang terkandung dalam biogas adalah metana 55 - $70 \%$ dan karbon dioksida $30-45 \%$ serta sejumlah kecil nitrogen dan hidrogen sulfida [3]. Tapi metana $\left(\mathrm{CH}_{4}\right)$ yang terutama dimanfaatkan sebagai bahan bakar. Apabila kandungan metana dalam biogas 
lebih dari 50\% maka biogas tersebut telah layak digunakan sebagai bahan bakar. Tabel 1 menunjukan komposisi biogas secara umum.

Tabel 1. Komposisi Biogas Secara Umum [3]

\begin{tabular}{|l|c|}
\hline \multicolumn{1}{|c|}{ Komposisi Biogas } & Jumlah \\
\hline Metana $\left(\mathrm{CH}_{4}\right)$ & $55-70 \%$ \\
Karbon dioksida $\left(\mathrm{CO}_{2}\right)$ & $30-45 \%$ \\
Nitrogen $\left(\mathrm{N}_{2}\right)$ & $0-0,3 \%$ \\
Hidrogen Sulfida $\left(\mathrm{H}_{2} \mathrm{~S}\right)$ & $1-5 \%$ \\
\hline
\end{tabular}

Kandungan yang terdapat dalam biogas dapat mempengaruhi sifat dan kualitas biogas sebagai bahan bakar. Kandungan yang terdapat dalam biogas merupakan hasil dari proses metabolisme mikroorganisme. Biogas yang kandungan metananya lebih dari $45 \%$ bersifat mudah terbakar dan merupakan bahan bakar yang cukup baik karena memiliki nilai kalor bakar yang tinggi. Tetapi jika kandungan $\mathrm{CO}_{2}$ dalam biogas sebesar $25-50 \%$ maka dapat mengurangi nilai kalor bakar dari biogas tersebut. Sedangkan kandungan $\mathrm{H}_{2} \mathrm{~S}$ dalam biogas dapat menyebabkan korosi pada peralatan dan perpipaan dan nitrogen dalam biogas juga dapat mengurangi nilai kalor bakar biogas tersebut. Selain itu terdapat uap air yang juga dapat menyebabkan kerusakan pada pembangkit yang digunakan [3].

\section{Metodologi Penelitian}

Bahan baku yang digunakan pada penelitian ini adalah limbah cair kelapa sawit dari berbagai pabrik kelapa sawit yaitu, PKS Pagar Merbau, PKS Sisirau dan PKS Rambutan. Penelitian dilakukan dengan proses fermentasi anerobik termofilik menggunakan fermentor jenis Continous Stirred Tank Reactor (CSTR) dengan volume 2 liter, pengadukan 100-110 rpm dan HRT 6 hari. Analisa yang dilakukan pada penelitian ini meliputi analisa cairan pada limbah yang belum difermentasi dan dengan limbah yang sudah difermentasi. Analisa cairan ini terdiri dari : kadar total solid (TS), abu (ash), volatile solid (VS), BOD, COD dan M-alkalinitas. Volume biogas yang dihasilkan juga diukur perharinya menggunakan wet gas meter. Rangkaian penelitian diperlihatkan pada Gambar 1.

Pada awal percobaan, fermentor diberi umpan POME dengan HRT 80 hari. Bila kinerja fermentasi dinilai baik berdasarkan volume biogas yang dihasilkan dan M-alkalinitas, maka laju HRT dapat diturunkan dengan menambah laju umpan harian sebesar 20\%. Pengumpanan dilakukan secara otomatis dengan bantuan timer sebanyak 4 kali sehari. Temperatur fermentor diatur sehingga termofilik sekitar $55^{\circ} \mathrm{C}$ dengan $\mathrm{pH}$ dijaga konstan antara 6,5 - 8. Untuk setiap 1 liter umpan LCPKS, ditambahkan $300 \mu \mathrm{L}$ campuran logam $\left(\mathrm{FeCl}_{2}\right.$, $\mathrm{NiCl} .6 \mathrm{H}_{2} \mathrm{O}$ dan $\left.\mathrm{CoCl}_{2} \cdot 6 \mathrm{H}_{2} \mathrm{O}\right)$ dan sebagai nutrisi ditambahkan 1,13 gram/liter $\mathrm{NH}_{4} \mathrm{HCO}_{3}$ untuk mencukupi kebutuhan nitrogen. Campuran diaduk rata sebelum dimasukkan ke dalam tangki umpan.

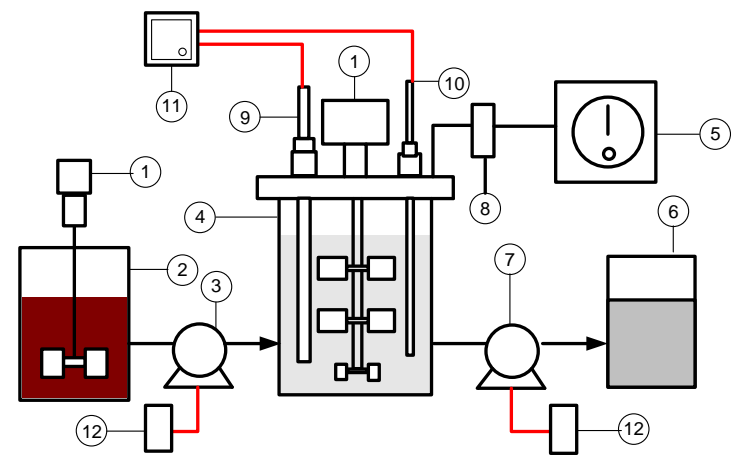

Keterangan:
1. Mixer
2. Tangki Pencampur
3. Pompa Inlet
4. Fermentor
5. Gas Meter
6. Tangki Keluaran
7. Pompa Outlet
8. $\mathrm{H}_{2} \mathrm{~S}$ Adsorber
9. Termometer
10. pH Meter
11. Data Logger
12. Timer

Gambar 1. Rangkaian Peralatan Penelitian

\section{Hasil}

a. Perbandingan Hasil Karakteristik LCPKS dan Cairan

Keluaran Fermentasi dari Berbagai PKS

Tabel 2 memperlihatkan hasil karakterisasi limbah cair segar yang diambil dari tiga lokasi yang berbeda yaitu PKS Rambutan, PKS Pagar Merbau dan PKS Sisirau dan juga cairan keluaran fermentor.

Tabel 2. Karakteristik LCPKS dan cairan keluaran fermentor

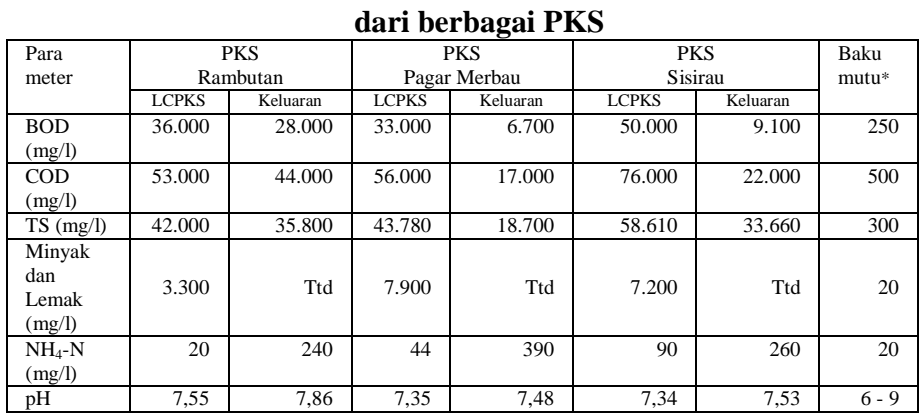

*) Sumber: Keputusan Menteri LH No: Kep.51/MENLH/10/1995)

Ttd $=$ tidak terdeteksi

Tabel 2 memperlihatkan bahwa nilai parameter BOD, COD, TS, minyak dan lemak dan $\mathrm{NH}_{4}-\mathrm{N}$, baik untuk LCPKS segar maupun untuk keluaran fermentor berada diatas ambang baku mutu limbah sehingga limbah tersebut tidak boleh dibuang ke sembarang tempat karena berdampak negatif terhadap lingkungan, sehingga diperlukan pengolahan lebih lanjut agar berada di bawah baku mutu. Sedangkan parameter pH masih berada di antara 6-9 baku mutu limbah.

Berdasarkan Tabel 2 juga dapat dilihat parameter BOD, COD, TS, minyak dan lemak antara LCPKS dan keluaran mengalami penurunan akibat terjadinya fermentasi sehingga nilai pada keluarannya juga mengalami penurunan. Sedangkan 
nilai pada parameter $\mathrm{NH}_{4}-\mathrm{N}$ antara LCPKS dan keluaran mengalami peningkatan karena adanya penambahan zat kimia yaitu natrium bikarbonat $\left(\mathrm{NaHCO}_{3}\right)$ dan amonium bikarbonat $\left(\mathrm{NH}_{4} \mathrm{HCO}_{3}\right)$ sehingga nilai tersebut mengalami peningkatan.

\section{b. Perbandingan Produksi Biogas Antara PKS Rambutan, PKS Pagar Merbau dan PKS Sisirau}

Gambar 2 memperlihatkan produksi biogas yang dihasilkan dari fermentasi limbah cair pabrik kelapa sawit yang diambil dari tiga lokasi yang berbeda yaitu PKS Rambutan, PKS Pagar Merbau dan PKS Sisirau.

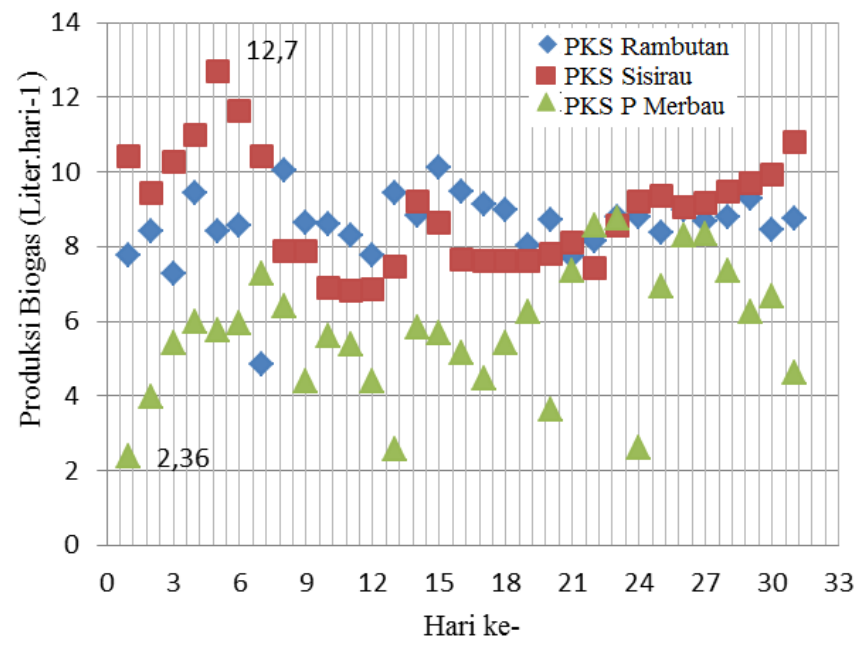

Gambar 2. Perbandingan Produksi Biogas dari Berbagai LCPKS

Dari gambar 2 dapat dilihat perbandingan produksi biogas antara limbah cair kelapa sawit dari berbagai PKS. Limbah cair kelapa sawit dari PKS Sisirau memiliki tingkat produksi biogas yang lebih tinggi sebesar 12,7 liter/hari dibandingkan PKS yang lain. PKS Pagar Merbau menghasilkan biogas dengan nilai terendah yaitu sebesar 2,36 liter/hari. Tetapi jika dilihat dari kestabilan dalam memproduksi biogas, limbah cair dari PKS Rambutan relatif memiliki kestabilan yang bagus dalam memproduksi biogas. Hal ini sesuai dengan teori yang menyebutkan bahwa variasi dari sifat-sifat biokimia menyebabkan produksi biogas juga bervariasi. Sejumlah bahan organik dapat digunakan bersamasama dengan beberapa persyaratan produksi gas atau pertumbuhan normal bakteri metan yang sesuai. Beberapa sifat bahan organik tersebut mempunyai dampak yang nyata pada tingkat produksi gas [5].

\section{c. Perbandingan TS dan VS Antara PKS Rambutan, PKS Pagar Merbau dan PKS Sisirau}

Total Solid (TS) digunakan untuk mengetahui jumlah bahan kering (meliputi abu dan bahan organik) yang terdapat dalam suatu bahan. Dengan kata lain, air dalam bahan harus diuapkan untuk mengetahui nilai ini [1]. Gambar 3 dan 4 memperlihatkan perbandingan TS dan VS dari fermentasi limbah cair pabrik kelapa sawit yang diambil dari tiga lokasi yang berbeda yaitu PKS Rambutan, PKS Pagar Merbau dan PKS Sisirau.

Dari Gambar 3 diperlihatkan bahwa limbah cair kelapa sawit dari PKS Sisirau memiliki kandungan total solid yang lebih tinggi daripada PKS Rambutan dan Pagar Merbau, penyebab perbedaan Total Solid diantara ketiga PKS adalah kandungan COD yang cukup tinggi diantara ketiga PKS tersebut.

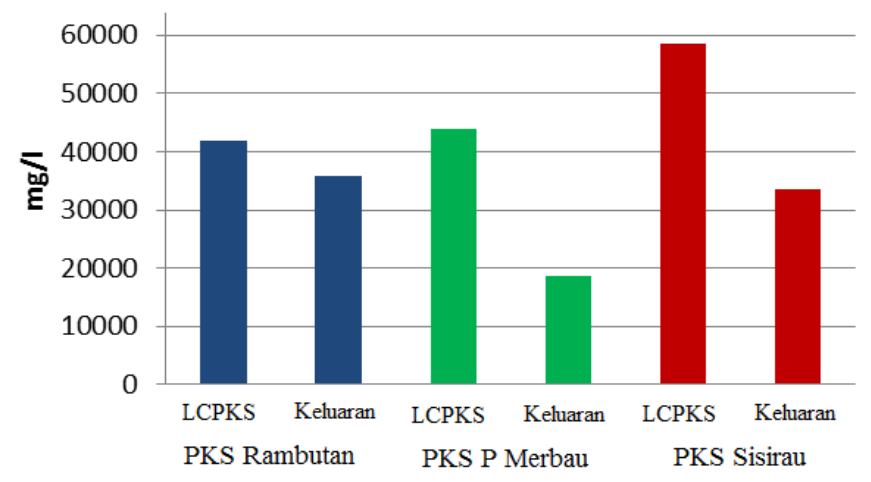

Gambar 3. Perbandingan Total Solid (TS) dari Berbagai LCPKS

Volatile Solid (VS) digunakan untuk mengetahui jumlah bahan organik yang terkandung dalam bahan, yang dapat dikonversikan menjadi metana dan karbondioksida dalam proses anaerob. Cara untuk mengetahuinya adalah dengan mencari terlebih dahulu, kadar abu yang diperoleh dengan memanaskan bahan kering hingga temperatur $700{ }^{\circ} \mathrm{C}$ selama 2 jam untuk menghilangkan atau menguapkan bahan padat volatile [1].

Gambar 4 menunjukkan bahwa limbah cair kelapa sawit dari PKS Sisirau memiliki jumlah bahan organik yang terkandung dalam bahan, yang dapat dikonversikan menjadi metana dan karbondioksida dalam proses anaerob yang lebih tinggi daripada PKS Rambutan dan Pagar Merbau.

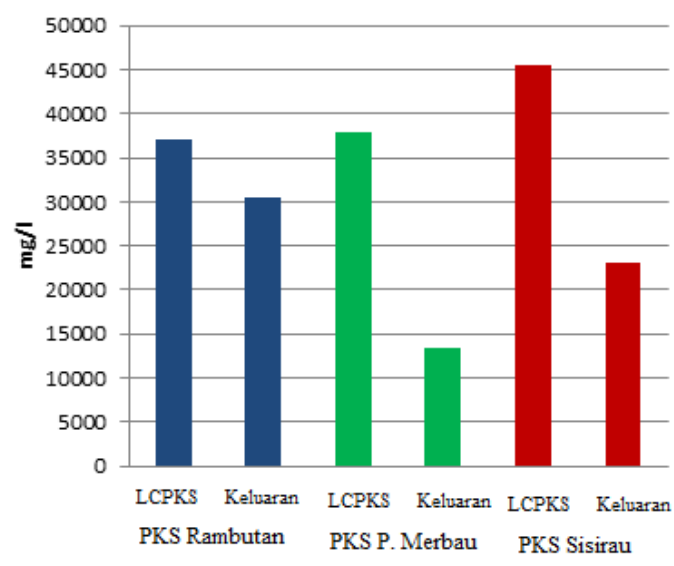

Gambar 4. Perbandingan Volatile Solid (VS) dari Berbagai LCPKS 


\section{Kesimpulan}

Dari hasil penelitian yang telah dilakukan dapat disimpulkan beberapa hal bahwa limbah cair kelapa sawit yang diambil dari PKS Sisirau menghasilkan biogas terbanyak yakni sebesar 12,7 liter/hari, selain itu memiliki nilai Total Solid (TS) sebesar $58.610 \mathrm{mg} / \mathrm{l}$ dan Volatile Solid (VS) sebesar $45.400 \mathrm{mg} / \mathrm{l}$ sehingga sangat bagus jika digunakan untuk menghasilkan biogas. Selain itu diperoleh parameter BOD PKS Rambutan sebesar 28.000 mg/l, COD 44.000 mg/l, TS $35.800 \mathrm{mg} / \mathrm{l}$ dan $\mathrm{NH}_{4}-\mathrm{N}$ sebesar $240 \mathrm{mg} / \mathrm{l}$. Parameter BOD PKS Pagar Merbau sebesar $6.700 \mathrm{mg} / \mathrm{l}$, COD sebesar 17.000, TS sebesar $18.700 \mathrm{mg} / \mathrm{l}$ dan $\mathrm{NH}_{4}-\mathrm{N}$ sebesar $390 \mathrm{mg} / \mathrm{l}$. Parameter BOD PKS Sisirau sebesar $9.100 \mathrm{mg} / \mathrm{l}$, COD sebesar 22.000, TS sebesar $33.660 \mathrm{mg} / \mathrm{l}$ dan $\mathrm{NH}_{4}-\mathrm{N}$ sebesar $260 \mathrm{mg} / \mathrm{l}$. Ketiga PKS tersebut berada diatas ambang baku mutu limbah yang dipersyaratkan oleh pemerintah RI sehingga masih membutuhkan pengolahan lanjutan.

\section{Ucapan Terima Kasih}

Penulis mengucapkan terima kasih sebesar-besarnya kepada Metawater Co. Ltd. Jepang dan Fakultas Teknik USU yang telah membiayai penelitian ini.

\section{Daftar Pustaka}

[1] Chesshire, M. 2005, Biogas from Energy Crops and Agrowastes, http://www.jyu.fi/science/muut_yksikot/ summerschool/en/history/JSS15report.pdf. [diakses 10 September 2008]

[2] Chisti Y, Biodiesel from microalgae, Biotechnology Advances, 25, 2007, 294-306.

[3] Deublein, D dan Steinhauster, A., Biogas from Waste and Renewable Resources. An Introduction, WILEYVCH Verlag GmbH \& Co. KGaA, Weinheim, 2008.

[4] Pertus Nugro Rahardja, Studi banding teknologi pengolahan limbah cair pabrik kelapa sawit. Jurnal Teknik Lingkungan, Vol.10 No.1, Jakarta, 2009, ISSN 1441-318X.

[5] Wahyuni, S. Biogas, Penebar Swadaya, Jakarta, 2008.

[6] Wintolo, Marhento dan Rochman Isdiyanto, Prospek Pemanfaatan Biogas dari Pengolahan Air Industri Tapioka, Pusat Penelitian dan Pengembangan Ketenagalistrikan dan Energi Terbarukan, vol. 10, no. 2, 2011, 103-112. 